\title{
PROCEDIMENTOS DE FISIOTERAPIA DERMATOFUNCIONAL NO REJUVENESCIMENTO FACIAL
}

\section{REVISÃO DE LITERATURA}

BESSA, Vicente Alberto Lima ${ }^{1}$

BESSA, Vicente Alberto Lima. Procedimentos de fisioterapia dermatofuncional no rejuvenescimento facial. Revista Científica Multidisciplinar Núcleo do Conhecimento. Ano 06, Ed. 09, Vol. 05, pp. 05-26. Setembro de 2021. ISSN: 24480959, Link de acesso: https://www.nucleodoconhecimento.com.br/saude/fisioterapiadermatofuncional, DOI: 10.32749/nucleodoconhecimento.com.br/saude/fisioterapiadermatofuncional

\section{RESUMO}

O envelhecimento é um processo natural de qualquer ser vivo e representa o declínio inevitável e irreversível das funções das estruturas do corpo. Ele também promove um impacto emocional e estético, logo muitos procuram desacelerá-lo ao manter uma vida mais saudável pela boa alimentação, prática de exercícios e procedimentos estéticos. Desacelerar o envelhecimento da face é possível através da fisioterapia dermatofuncional que emprega um arsenal de tratamentos estéticos. No entanto, surgiu a seguinte questão: quais os principais procedimentos que podem ser utilizados no rejuvenescimento facial na fisioterapia dermatofuncional? Para responder a está questão foi desenvolvido um estudo que objetivou investigar os principais tratamentos estéticos e seus efeitos terapêuticos utilizados para manter a pele da face mais jovem e saudável. Para tanto, foi realizado uma pesquisa revisão de literatura sobre os tratamentos estéticos antienvelhecimento da face, os quais se encontram disponíveis nas bases de dados da PubMed, Semantic Scholar, Scielo, BVS-BIREME e Science Direct. Concluiu-se que os principais procedimentos utilizados são: radiofrequência, laser, luz intensa pulsada, led, microcorrentes,

\footnotetext{
${ }^{1}$ Mestre.
}

RC: 97346

Disponível em: https://www.nucleodoconhecimento.com.br/saude/fisioterapiadermatofuncional 
eletrolifting, microagulhamento, micropuntura, peelings, acupuntura e cosméticos. Pode-se inferir que a fisioterapia dermatofuncional possui um vasto arsenal a sua disposição para hidratar, nutrir, melhorar o tônus cutâneo e muscular, despigmentar, estimular a síntese de colágeno e elastina, ter ações antioxidante, antiglicante e desglicante que resultam em uma pele mais jovial e saudável.

Palavras-chave: tratamento de rejuvenescimento, tratamento antienvelhecimento, estética facial.

\section{INTRODUÇÃO}

As projeções feitas pela Organização Mundial da Saúde estimam mais de 800 milhões de pessoas com idade superior a 65 anos no mundo em 2025 (PORTELA e DUTRA, 2019). E conforme a expectativa de vida da população tende a aumentar, cresce também a busca para manter um padrão de beleza com uma pele jovial, sem manchas e sem rugas. É fato que todos desejamos viver por mais tempo e de forma hígida, por isso muitos procuram um estilo de vida mais saudável, e neste caso se incluem os procedimentos estéticos.

No entanto, todo ser vivo está predestinado a envelhecer e o processo de envelhecimento cutâneo é resultado de fatores intrínsecos e extrínsecos que produzem diversas alterações na arquitetura facial e reduz progressivamente a capacidade de homeostase do organismo (PEREIRA et al., 2019).

Mas, para atender as necessidades do ser humano em se manter saudável e belo, a ciência evoluiu muito e, atualmente, há diversos tratamentos que amenizam o envelhecimento facial desde cosméticos, agentes físicos, acupuntura e até cirurgias. Embora a cirurgia estética seja muito procurada pelas pessoas para retardar ou minimizar os sinais de envelhecimento facial, há outros procedimentos não cirúrgicos muito eficientes. Esses procedimentos não cirúrgicos têm a vantagem de propiciar rejuvenescimento cutâneo através de técnicas rápidas e seguras que contribuem para o bem-estar de seus simpatizantes (PORTELA e DUTRA, 2019). 
Nesse contexto, a fisioterapia dermatofuncional tem sido uma aliada do ser humano para manter a pele mais jovial e saudável e corrigir algumas de suas imperfeições. É sabido que há diversos recursos físicos e cosméticos que contribuem para o rejuvenescimento da pele. Portanto, surge a seguinte questão norteadora: quais os principais procedimentos que podem ser utilizados no rejuvenescimento facial na fisioterapia dermatofuncional?

Para compreender melhor a atuação do fisioterapeuta foi desenvolvida uma pesquisa de revisão de literatura, cujo objetivo foi investigar os principais tratamentos estéticos e seus efeitos terapêuticos utilizados para manter a pele da face mais jovem e saudável.

Foi feita uma análise das pesquisas publicadas sobre os tratamentos estéticos antienvelhecimento da face, os quais se encontram disponíveis nas bases de dados da PubMed, Semantic Scholar, Scielo, BVS-BIREME e Science Direct, abrangendo os últimos 13 anos. Utilizou como descritores: tratamento de rejuvenescimento, tratamento antienvelhecimento e estética facial. Como critérios de inclusão estão os artigos, livros e trabalhos acadêmicos em português e inglês que discorram sobre os tratamentos estéticos de rejuvenescimento não invasivo e minimamente invasivo. Já como critérios de exclusão foram artigos sem caráter científico e aqueles que abordem procedimentos estéticos que não possam ser prescritos pelo fisioterapeuta.

Foram coletados 80 materiais entre artigos, livros e trabalhos acadêmicos que discorriam sobre o tema, porém, destes foram selecionados 37 artigos, 2 livros e 1 tese para o estudo.

\section{DESENVOLVIMENTO}

É mister ressaltar que o envelhecimento diminui a função dos órgãos e sistemas do corpo, inclusive da pele. Sabe-se que o envelhecimento da pele é influenciado pela hereditariedade, mas, sobretudo pela exposição solar. Esses fatores promovem alterações epidérmicas, tais como: diminuição de potencial proliferativo, disfunção 
dos melanócitos, das células de Langerhans e da adesão dermo-epidérmica; além de alterações na derme, tais como: diminuição da espessura, da celularidade e vascularização, degeneração do colágeno (MORAES, 2008). Pode-se afirmar que a pele é o órgão que mais se evidencia o envelhecimento (PORTELA e DUTRA, 2019). Entretanto, os sinais e a intensidade do envelhecimento facial natural podem ser reduzidos através de condutas de fisioterapia dermatofuncional.

É mister destacar que é possível classificar o envelhecimento da pele em intrínseco ou cronológico ou actinoscenescência que é causado pela programação genética e extrínseco ou fotoenvelhecimento oriundo das condições ambientais externas, tais como, irradiação ultravioleta, vento, calor e tabaco.

Para explicar o envelhecimento, várias teorias biológicas surgiram, porém, os mecanismos envolvidos no processo ainda não são totalmente conhecidos. Há três grupos de teorias biológicas propostas por Weinert e Timiras: teorias evolutivas, teorias sistêmicas e teorias do envelhecimento no nível molecular-celular (TEIXEIRA e GUARIENTO, 2010).

As teorias evolutivas explicam que o envelhecimento está relacionado a múltiplos fatores como o acúmulo de mutações que afetam a saúde com avançar da idade; genes que são benéficos quando a pessoa é jovem mais se tornam prejudiciais na fase pós-reprodutiva; e células somáticas que permanecem saudáveis para garantir a reprodução, mas são descartáveis após o período reprodutivo. Já as teorias do envelhecimento no nível molecular-celular envolvem a possibilidade de erros na síntese proteica; danos moleculares acumulados no DNA; encurtamento dos telômeros; metabolismo oxidativo que produz radicais livres altamente reativos; os produtos finais de glicosilação avançada se acumulam nas proteínas da matriz extracelular durante o envelhecimento; e morte celular programada. Por sua vez, as teorias sistêmicas abordam alterações no sistema neuroendócrino que prejudicam a homeostase; declínio da função do sistema imunológico que aumenta a incidência de doenças autoimunes; e ritmo da vida que considera que consumo de energia representa uma limitação na longevidade (TEIXEIRA e GUARIENTO, 2010). 
As teorias que explicam o envelhecimento são importantes para o desenvolvimento de tecnologia cosmética e de equipamentos que possam desacelerar os danos na pele que podem ser tratados pela estética. É evidente que as teorias do envelhecimento não se restringem a pele, mas é referente ao organismo na totalidade. Porém, a busca para retardar o envelhecimento é um fato. E em relação ao envelhecimento da pele, a fisioterapia tem contribuído de forma significativa.

Com o passar do tempo, surgiram grandes avanços nos tratamentos de envelhecimento, principalmente com o advento de diversas técnicas não invasivas que buscam tratar discromias, rugas e linhas de expressão, flacidez cutânea e muscular com procedimentos de rápida recuperação e sem interferência nos afazeres cotidianos dos clientes.

Logo, em todo o mundo há esforços a fim de desacelerar do processo de envelhecimento da pele e, por isso, há um crescimento do mercado da indústria do antienvelhecimento. Tratamentos estéticos para pele têm sido propostos constantemente, seja por meio de cosméticos, aparelhos, cirurgias e modalidades alternativas. Muitos buscam saúde e estética para pele, principalmente o público feminino.

Todavia, e bom destacar que os tratamentos estéticos para pele não são privilégio exclusivo do público feminino, visto que os homens já têm demonstrado muito interesse neste tipo de terapia. Os mesmos recursos cosméticos, eletroterapêuticos, termoterapêuticos, fototerapêuticos que são utilizados no público feminino podem ser aplicados nos homens. Porém, a indústria cosmética já tem desenvolvido uma linha cosmética exclusiva para os homens (PEREIRA et al., 2019).

Uma revisão integrativa a partir da análise 8 artigos descreveu os tipos de tratamentos estéticos que podem ser empregados para atenuar o envelhecimento cutâneo. O resultado do estudo indicou que os procedimentos mais comuns empregados nos cuidados com a pele para suavizar as rugas, remodelar a pele e melhorar a textura são: radiofrequência, laser, luz intensa pulsada, led, 
microcorrentes, eletrolifting, microagulhamento, micropuntura, peelings e cosméticos (NOVAIS e DE SOUZA, 2020). Além desses procedimentos, há o emprego de terapia alternativa, como a acupuntura para manter uma pele jovem.

Essa técnica milenar já vem sendo incorporada como alternativa terapêutica por fisioterapeutas há décadas para tratar diversos tipos de doenças e, atualmente, ela é mais uma aliada das técnicas anti-aging para a face. Ela tem a vantagem de ser indolor, tem baixo custo financeiro, resultados rápidos e sem efeitos colateriais (CRUZ e PEREIRA, 2018). Logo, a acupuntura pode desacelerar o envelhecimento facial, visto que melhora o funcionamento dos órgãos internos e sistemas, fato este que suaviza as linhas de expressão, tonifica os músculos, melhora a vascularização e nutrição local e melhora o aspecto geral da pele (SANTOS; NASCIMENTO e BRITO, 2018).

É sabido que desde 2003, a acupuntura tornou-se uma tendência alternativa utilizada no tratamento antienvelhecimento e acredita-se que seus efeitos terapêuticos para este fim tenham sido descobertos acidentalmente, enquanto se tratava de outras doenças. Para a Medicina Tradicional Chinesa, a acupuntura consiste na introdução de agulhas em pontos da face e corpo para propiciar um equilíbrio local e sistêmico. É sabido que há uma correspondência entre a face e os órgãos, a exemplo tem-se a orelha que se relaciona com os rins, a linha horizontal acima do lábio superior que se relaciona com ovários e o útero (CRUZ e PEREIRA, 2018).

Já para a acupuntura facial, a agulha irá produzir duas ações, uma é local que representa uma injuria na pele que responde com produção de colágeno e elastina para reparar o dano; outra é a estimulação do equilíbrio dos órgãos em consequência da representação dos Zang Fu (órgãos e vísceras) na face (CRUZ e PEREIRA, 2018).

Há evidências científicas que comprovam a redução de rugas na face por intervenção da acupuntura. Um estudo que objetivou avaliar a efetividade da 
acupuntura para redução da profundidade, área e volume de rugas do terço superior da face foi realizado através de um ensaio clínico randomizado com crossover parcial. Participaram da pesquisa 87 mulheres entre 40 e 65 anos com rugas com graus III e IV na escala de Glogau. Elas foram distribuídas aleatoriamente em 3 grupos: 27 no grupo controle, 31 no grupo acupuntura e 29 no grupo eletroacupuntura. Foi realizada avaliações antes da primeira sessão e após a última sessão para medir a profundidade, área e volume da ruga por meio de análise fotográfica processada em dois softwares livres (ImageJ e IDEA), além da utilização do checklist adaptado (Guideline Face-Q e Arizola) a percepção das participantes sobre as rugas e a aparência. As voluntárias foram submetidas a 8 sessões de 30 minutos, 2 vezes por semana. E pode-se evidenciar que nos grupos de acupuntura e eletroacupuntura obtiveram redução nas medidas de profundidade, área e volume das rugas na região da glabela e testa comparados ao grupo controle. Constatou-se melhora entre a $4^{\mathrm{a}}$ e $5^{\mathrm{a}}$ sessão (SOUZA, 2020).

Outro estudo que resultou em benefícios estéticos facial através da acupuntura foi realizado no Hospital Universitário de Kyung Hee em Gangdong na Coreia do Sul em 2011. O estudo teve como hipótese que a acupuntura cosmética facial afeta a elasticidade facial ao restaurar o tônus do músculo da mímica em repouso por meio da inserção de agulhas nos músculos da cabeça, face e pescoço. Para tanto, foi realizada um estudo piloto de rótulo aberto e de braço único no qual 28 participantes foram elegíveis, porém apenas 27 completaram o estudo. As participantes eram mulheres com média de 50,04 $\pm 6,07$ (variação: 40-59) anos com grau III na escala de Glogau e foram avaliadas antes e após as cinco sessões pelos critérios de topografia Moiré e pela escala de autoavaliação da elasticidade facial orientada. Elas foram submetidas a 5 sessões ao longo de 3 semanas. $O$ resultado foi uma melhora significativa constatada pela topografia de Moiré e pela pontuação na autoavaliação da elasticidade das voluntárias (YUN et al., 2013).

Além da acupuntura há tratamentos mais convencionais utilizados na estética facial, como a radiofrequência que é excelente para melhorar o tônus cutâneo. Esse recurso aquece os tecidos gerando um efeito tensor imediato em função da redução

RC: 97346

Disponível em: https://www.nucleodoconhecimento.com.br/saude/fisioterapiadermatofuncional 
de feixes de colágeno, mas também estimula o aumento da produção de colágeno. Ela é um excelente método não invasivo para tonificar a pele e tecido mole, o que propicia a redução das rugas nasolabiais, da papada e melhor definição do ângulo cervicomentoniano.

É sabido que a radiofrequência representa uma tecnologia em gera uma ação térmica tissular que promove resultados satisfatórios para atenuar marcas típicas do envelhecimento cutâneo, logo ela é benéfica para o processo de rejuvenescimento facial. Todavia, o aumento da temperatura também pode causar danos celulares, por isso é necessário a padronização da temperatura ideal a ser prescrita nos tratamentos. Estudos concluíram que as temperaturas variando entre $37^{\circ}$ e $40^{\circ}$ Celsius apresentam melhores resultados do tratamento das rugas e flacidez da pele (SANTOS et al., 2020).

Há diversos estudos que comprovam a eficácia da radiofrequência no tratamento do envelhecimento facial. Dentre eles, há um estudo de caso de natureza básica, qualiquantitativo de caráter exploratório que objetivou analisar os efeitos do tratamento de radiofrequência no envelhecimento facial em linhas e rugas de expressões, particularmente as periorbitais e sulcos nasogenianos em mulheres. Nele, 5 voluntárias entre 30 e 50 anos foram submetidas a 9 sessões de tratamento. Todas foram avaliadas antes e após o tratamento de radiofrequência por meio de avaliação fotográfica e questionários. Em cada sessão houve a higienização da pele e a aplicação por 10 minutos da terapia com potência de 60W nas sessões iniciais e $70 \mathrm{~W}$ nas subsequentes. A temperatura foi controlada entre 39 e $41^{\circ} \mathrm{C}$. Ao término de cada sessão era aplicado hidratante facial e protetor solar FPS 60. O resultado foi um índice de 9,6 de satisfação e melhora na aparência da pele, tanto na hidratação quanto na textura, firmeza e elasticidade (CASTRO e MENSCH, 2017).

Outro estudo, realizado em 2018, destacou os benefícios da radiofrequência com o objetivo de avaliar as evidências científicas publicadas sobre os seus efeitos para o tratamento das rugas e da flacidez facial. Para tanto, foi realizada uma revisão sistemática da literatura com metanálise sobre a radiofrequência no envelhecimento

RC: 97346

Disponível em: https://www.nucleodoconhecimento.com.br/saude/fisioterapiadermatofuncional 
cutâneo facial. Foi desenvolvido um estudo que avaliou a qualidade metodológica dos estudos de radiofrequência no envelhecimento cutâneo facial com base dos 27 itens pontuáveis publicado por Downs e Black em 16 pesquisas. A maior parte dos estudos faz utilização de registros fotográficos, porém 2 fizeram análise histológica. Constatou-se melhora nas regiões periorbital e nasolabial pelos avaliadores, logo há evidências clínicas suficientes para afirmar que radiofrequência diminuiu a flacidez e as rugas na região da face diante da altas temperaturas (MENDONÇA et al., 2018).

Um estudo importante foi realizado no Hospital de Dermatologia em Yongin, Gyeonggi-do, Coreia do Sul e contou com a participação de 30 mulheres entre $30 \mathrm{e}$ 55 anos de idade. Foram investigados os efeitos da terapia a laser de baixa potência (não ablativa) ou low-level light therapy (LLLT), eletroacupuntura (EA) e radiofrequência (RF) na pigmentação e tom de pele da face nas voluntárias. As participantes foram divididas em 3 grupos de 10 componentes, a saber: grupo LLLT, grupo EA e grupo RF. Foram realizadas 2 sessões semanais de 15 minutos por um período de 6 semanas. Sendo que a análise do tom de pele foi feita antes e depois da intervenção. Pode-se inferir que o grupo LLLT não apresentou melhora significativas na pigmentação da pele pós-intervenção, porém houve aumento no tom da pele na região frontal e em ambas as bordas dos olhos. Já o grupo EA resultou em redução significativa na pigmentação nas bordas de ambos os olhos, assim como na bochecha esquerda, mas sem alterações significativas no tom da pele. O grupo RF apresentou diminuição pós-intervenção na pigmentação sob o olho esquerdo, bem como nas bordas de ambos os olhos e na bochecha esquerda e resultou em aumento significativo no tom da pele sob ambos os olhos. $O$ estudo concluiu que os 3 recursos tiveram efeitos positivos na pigmentação e tom de pele da face de mulheres adultas (KIM et al., 2016).

Deste modo, a tentativa de rejuvenescimento, sobretudo no aspecto facial, é possível com a utilização de tratamentos com laser (light amplification by stimulated emission of radiation, em português: amplificação da luz por emissão estimulada de radiação) e com luz intensa pulsada (intense pulse light, em português: luz intensa pulsada). A maior diferença entre o laser e a luz intensa pulsada é que o laser 
emprega uma tecnologia que produza radiação eletromagnética monocromática, coerente e colimado (única direção), enquanto o LIP emite feixes de luzes policromáticas, não coerentes e não colimadas (em várias direções).

É mister salientar que há diversos tipos de lasers utilizados para rejuvenescimento facial, pois são capazes de minimizar as rugas, marcas de expressão, cicatrizes de acne e manchas cutâneas e, desta forma, permitir uma aparência mais estética. Dentre os lasers empregados se destacam o tipo CO2, Nd-YAG pulso longo e Érbium-YAG, porém os mais agressivos para resurfacing ablativo são o laser de CO2 e o Érbium-YA. Por outro lado, os lasers menos agressivos são os não ablativos e, atualmente, o laser fracionamento representou mais um avanço nas técnicas de rejuvenescimento (SANTOS, 2019).

Assim sendo, o avanço da tecnologia tem proporcionado novos dispositivos para o rejuvenescimento facial e o tratamento de danos à pele. E isso inclui os lasers ablativos e não ablativos fracionados, apesar de não serem tão eficazes para a renovação cutânea quanto o laser tradicional, eles podem fornecer bons resultados com efeitos colaterais reduzidos. É bom ressaltar que a técnica fracionada permite uma regeneração mais eficiência do que a não fracionada, fato que abrevia o tempo de recuperação e reduzem as complicações (ZACHARY, 2016).

O laser ablativo fracionado representa uma boa estratégia para estimular a regeneração do colágeno em função do aquecimento dérmico e este fato conduz a um lifting facial. Esse fato pode ser comprovado com diversos estudos de campo, dentre eles há uma pesquisa utilizando lasers fracionados não ablativos 1340nm em alta energia com passagem única e em média energia com passagem tripla para avaliar o rejuvenescimento facial. Para tanto, foi feito um estudo clínico prospectivo, unicêntrico e comparativo no ambulatório de Dermatologia da Faculdade de Medicina de Jundiaí. Participaram 20 mulheres entre 40 e 70 anos, com fototipo I a IV na escala de Fitzpatrick e grau moderado na classificação de Glogau. As 15 voluntárias foram submetidas a 3 sessões do laser com intervalo de quatro semanas e outras 5 voluntárias participaram apenas de 2 sessões por impossibilidade pessoal 
de comparecer. A hemiface direita das voluntárias recebeu três passadas e resfriamento da pele com o laser fracionado não ablativo 1340nm (aparelho SIBERIAN) com fluência $90 \mathrm{~mJ}$ e duração de pulso 5',100mtz/cm². Já a hemiface direita recebeu uma passada com laser fracionado não ablativo $1340 \mathrm{~nm}$, com fluência $120 \mathrm{~mJ}$, duração de pulso $5,100 \mathrm{mtz} / \mathrm{cm}^{2}$. As voluntárias foram avaliadas em período de 6 a 24 meses através de análise fotográfica concernentes as variáveis manchas, rugas, porfirinas e aparência global. Como resultado houve diminuição das rugas em ambos os lados, mas a melhora das manchas foi significativa apenas no lado direito, porém não houve melhora em relação às porfirinas. A pesquisa concluiu que a pele ficou mais bonita e com aparência rejuvenescida, logo o laser surge como uma alternativa segura e eficaz para o rejuvenescimento facial (CAMPOS et al., 2017).

A luz intensa pulsada (LIP) é outra opção para tratar o envelhecimento, pois pode estimular o acréscimo de fibras colágenas e elásticas com diminuição das rugas e melhora na textura da cútis. Um estudo que relata os benefícios da LIP foi publicado em 2020 e objetivou verificar os benefícios da luz intensa pulsada no envelhecimento cutâneo. Nesse estudo bibliográfico foram analisadas publicações entre os anos de 2007 e 2019 através das bases de dados do Google Acadêmico, Scielo e PubMed. Pode-se inferir que a LIP é uma terapia apropriada para peles envelhecidas visto que este recurso pode estimular o fibroblasto a produzir colágeno e elastina, reduzindo as rugas e marcas de expressão, além de melhorar a textura da pele (STROPARO e DE SANTIS, 2020).

Uma pesquisa realizada com em 26 mulheres entre 40 e 65 anos, com fototipos II e III de Fitzpatrick e grau III na escala de Glogau foi desenvolvida para estudar a ação da luz intensa pulsada no fotoenvelhecimento e na resposta imunológica cutânea. $O$ estudo clínico e histopatológico avaliou as células de Langerhans (CD1), a expressão da molécula de adesão intercelular, de linfócitos CD4 e CD8 e a quantificação de colágeno e as fibras elásticas. As voluntárias foram avaliadas histológica e imuno-histoquímicamente pré e pós-tratamento (6 meses), além de fotograficamente. A pele foi preparada com ácido retinoico $0,025 \%$ mais

RC: 97346

Disponível em: https://www.nucleodoconhecimento.com.br/saude/fisioterapiadermatofuncional 
hidroquinona 4\% na face durante a noite. A aplicação da LIP consistiu em 5 sessões com intervalo mensal com o equipamento israelense Record 618 que possui um comprimento de onda largo (420 a 1100 nm). A duração do pulso único foi de 10 milissegundos, energia $20 \mathrm{~J} / \mathrm{cm}^{2}$ e resfriamento a ar, sendo feitas 3 passadas. Os resultados foram uma melhora clínica da pele de moderada a intensa em 76,92\% dos casos $(p<0,05)$; histologicamente constatou-se aumento de 51,33\% $(p<0,05)$ de fibras colágenas e $44,13 \%$ de fibras elásticas; a quantificação de células de Langerhans CD1 e dos linfócitos CD8 não tiveram diferenças significativas, mas ocorreu diminuição dos linfócitos CD4 com aumento da fração de área de pequenos vasos sanguíneos na derme. Fato que permitiu afirmar que o LIP promove rejuvenescimento da pele (PATRIOTA; RODRIGUES e CUCÉ, 2011).

Além do laser e da LIP, há outro tipo de fototerapia bastante empregado na área da estética denominado LED (light emitting diode, em português: diodo emissor de luz) que melhora a qualidade da pele. O led atua por meio da fotobiomodulação que permite estímulo de respostas antioxidantes, aumento da produção de ATP e, desta forma, atuando na melhora da qualidade da pele e rejuvenescimento (BORGES, SANTOS e MOLZ, 2019).

A fotobiomodulação pode ser obtida com o emprego de fototerapia a laser e a led dentro da faixa de luz que corresponde a 600-950nm, ou seja, as faixas vermelha e infravermelha. A fototerapia nessa faixa de espectro de luz permite estimular as mitocôndrias a aumentarem a síntese de ATP e, em consequência ao aumento da produção de ATP, há também o aumento na produção de superóxido que atua como antioxidante. Portanto, a fotobiomodulação melhora a qualidade da pele e promove o rejuvenescimento (BORGES; SANTOS e MOLZ, 2019).

Assim sendo, o led é empregado frequentemente na terapia de rejuvenescimento da pele devido ao seu mecanismo de fotobiomodulação. Ele é um procedimento seguro e indolor e para validar essa terapia vários estudos têm sido desenvolvidos. Um dos estudos foi um estudo experimental com ensaio clínico controlado e cego em voluntárias de 35 a 55 anos, residentes no município de Parnamirim/RN. As 
mulheres foram avaliadas com Protocolo de Avaliação Facial e análise fotográfica para avaliar o ângulo e medida do sulco nasogeniano, pelo software radiocef studio 2. Elas foram divididas em grupo controle (grupo 1) composto por 20 mulheres e grupo experimental (grupo 2) formado por outras 20. Porém, durante o estudo 16 voluntárias foram excluídas por desistirem ou abandonarem o tratamento. Sendo que 8 voluntárias pertenciam ao grupo 1 e 8 ao grupo 2, logo o resultado do estudo é referente a 24 voluntárias. O objetivo do estudo foi avaliar o efeito do LED no rejuvenescimento facial. O grupo 2 foi tratado com fototerapia com LED vermelho $(660 \mathrm{~nm})$, potência de 20 watts, por 20 minutos, em uma frequência de 2 sessões semanais, num total de 16 sessões. $O$ estudo concluiu que o led rejuvenesce a face, pois diminui a hipotonia cutânea evidenciado pelo aumento do ângulo nasogeniano e redução da medida do sulco nasogeniano (ESTRELA et al., 2014).

Logo, a integridade da epiderme e a estimulação no aumento da produção de colágeno na derme são possíveis com a aplicação de técnicas de rejuvenescimento não ablativas. Por exemplo, a luz intensa pulsada (LIP) permite um fotorrejuvenescimento não ablativo. É mister ressaltar que a LIP não é um laser, mas assim como o laser não-ablativo gera calor na pele sem cortes e é uma terapia que pode ser empregada contra o envelhecimento, flacidez e manchas na pele (SANTOS, 2019).

Um tratamento menos oneroso para o rejuvenescimento da pele é a microcorrente também chamada de MENS (Microcurrent Electrical Neuromuscular Stimulation). Ela é um tipo de eletroestimulação que emprega correntes de baixa intensidade (microampères) e baixa frequência, podendo apresentar correntes contínuas ou alternadas. Esse tipo de corrente tem como característica ser subsensorial, logo não gera desconforto ao cliente. A frequência do aparelho, em geral, pode ser ajudada entre $0,5 \mathrm{~Hz}$ e $900 \mathrm{~Hz}$ e a intensidade entre 10 e $1000 \mu \mathrm{A}$. Ela possui uma vantagem para peles envelhecidas por restabelecer a bioeletricidade tecidual, melhorar a oxigenação tecidual e incrementar o transporte ativo de aminoácidos, síntese de proteínas e ATP. 
A MENS tem sido frequentemente utilizada em tratamentos estéticos e há estudos relevantes sobre a sua eficácia. Um desses estudos analisou os efeitos da MENS em 6 voluntárias com rugas periorbitais, o seu grau de satisfação e de tolerância ao tratamento. As mulheres entre 45 e 60 anos foram avaliadas por técnica não invasivada viscoelasticidade da pele por sucção. Para tanto, utilizou-se o equipamento Cutometer ${ }^{\circledR}$ MPA580 da Courage \& Khazaka Electronic $\mathrm{GmbH}$ que permite a análise das propriedades mecânicas, firmeza e elasticidade da pele. Também foi aplicado um questionário sobre o índice de satisfação e o índice de tolerância. Para aplicar a MENS foi utilizado o aparelho Neurodyn Esthetic da Ibramed, cujo parâmetros foram: modo contínuo e forma de onda quadrada monopolar, com inversão de polaridade a cada 3 segundos, frequência $500 \mathrm{~Hz}$, intensidade variável de 10 a $990 \mu \mathrm{A}$, num total de 16 aplicações distribuídas em 2 sessões semanais. A pesquisa teve como resultado um aumento de $54,4 \%$ na firmeza na área periorbital esquerda e de $53,8 \%$ na área direita $(p<0,05)$. $O$ índice de satisfação e tolerância com o tratamento por MENS foi de $66,67 \%$, o que permitir inferir que o MENS melhora a firmeza da pele, logo contribui para a melhoria geral do seu aspecto (SANTOS, 2015).

Outro procedimento útil para tratar as rugas típicas do envelhecimento da pele é o eletrolifting também denominado galvanopuntura ou microgalvanopuntura. Consiste em uma terapia que utiliza a corrente galvânica na ordem de alguns microampères indicada para o tratamento de estrias, rítides e marcas de expressão. Essa terapia permite incrementar a vascularização, ação antioxidante, ampliar o número de fibroblastos jovens aumentando a síntese proteica, facilitar a migração de queratinócitos e macrófagos que resultará na reparação do tecido (BESSA e BESSA, 2019).

Um estudo de casos realizado em Santa Cruz do Sul, no Estado do Rio Grande do Sul, com 5 voluntárias entre 40 e 55 anos comparou a eficácia do eletrolifting isolado com eletrolifting associado a um nutricosmético para tratar o envelhecimento facial. As mulheres foram avaliadas por questionários através da Escala de Autoestima de Rosenberg (EAR) e questionário de satisfação modificado (Facial Outcome RC: 97346

Disponível em: https://www.nucleodoconhecimento.com.br/saude/fisioterapiadermatofuncional 
Evaluate), Self Perception Age (SPA) e da Escala Visual e Analógica (EVA) para dor, além de registro fotográfico. No grupo que houve a associação do eletrolifting com nutricosmético composto por vitaminas $\mathrm{A}, \mathrm{C}$ e $\mathrm{E}$, zinco, selênio e colágeno hidrolisado obteve melhor efeito rejuvenescedor nas rugas periorbiculares que 0 grupo que apenas foi submetido ao eletrolifting. Já a percepção da dor sofreu discreta variação. O resultado dos questionários foi mais satisfatório no grupo de eletrolifting com nutricosmético indicado aumento da autoestima, maior satisfação e sentimento de juventude na autopercepção da aparência com relação à idade (HELFER e MACHADO, 2017).

Outra pesquisa sobre o eletrolifting no tratamento do envelhecimento facial foi um estudo pré-experimental com 6 voluntárias entre 34 e 65 anos que possuíam rugas e/ou linhas de expressão na face. O estudo objetivou verificar os efeitos da corrente galvânica através da técnica de eletrolifiting no tratamento de rugas e/ou linhas de expressão. Todas as participantes foram avaliadas quanto ao tipo de pele, cor da pele, uso de protetor solar, uso de cosméticos e se há distúrbios circulatórios ou cicatrizes, além de registro fotográfico. $O$ tratamento foi composto de 10 sessões, 1 vez por semana e com intensidade variando de acordo com a sensibilidade de cada voluntária (entre 350 e 400 uA). O equipamento utilizado foi o Striat da Ibramed®. O resultado do estudo comprovou a satisfação das participantes e redução das rugas (BARBOSA e CAMPOS, 2013).

Para estimular a formação de colágeno a fim de rejuvenescer a pele é possível a aplicação da terapia de indução percutânea de colágeno (IPC) que é um procedimento tem como base $o$ uso de microagulhas que causam microlesões para estimular uma resposta ao processo inflamatório. A IPC pode ser obtida tanto com a micropuntura (com dermógrafo) quanto com o microagulhamento (com dermaroller ou dermapen), sendo que a grande diferença é que micropuntura é utilizada para tratar as linhas e cicatrizes de maneira concentrada e pontual. Já o microagulhamento é uma técnica que abrande uma área maior, contudo, sem muita concentração em linhas específicas.

RC: 97346

Disponível em: https://www.nucleodoconhecimento.com.br/saude/fisioterapiadermatofuncional 
É sabido que quando a IPC é aplicada irá provocar uma injuria na pele que pode alcançar até a derme. A perfuração da agulha pode romper a barreira cutânea e alguns capilares, o que pode gerar sangramento. Inicialmente, há a liberação de plaquetas e neutrófilos que são responsáveis por liberar os fatores de crescimento de transformação (TGF- $\alpha$ e TGF- $\beta$ ), fator de crescimento derivado das plaquetas (PDGF), fator de crescimento insulínico (IGF), fator de crescimento endotelial vascular (VEGF). Por sua vez a dissociação dos queratinócitos promove a liberação de citocinas (interleucina -1 $\alpha$, interleucina-8, interleucina-6, TNF- $\alpha$ e GM-CSF). Em uma 2a fase começa a cicatrização, no qual os neutrófilos são substituídos pelos monócitos e nesta fase ocorre o processo de angiogênese, epitelização, proliferação de fibroblastos e indução de colágeno tipo III, elastina, glicosaminoglicanos e proteoglicanos. Os monócitos secretam fatores de crescimento dos fibroblastos (TGF- $\alpha$ e o TGF- $\beta$ ) possibilitando a formação de novo colágeno. Numa fase mais tardia, o colágeno tipo III é substituído pelo colágeno tipo I que é mais duradouro (LIMA; LIMA e TAKANO, 2013).

A IPC aplicada isoladamente já estimula a formação de colágeno e rejuvenesce a pele, porém a eficácia do tratamento será muito maior se associada aos cosméticos. É importante destacar que essa técnica facilita a permeação dos princípios ativos (drug delivery), pois as agulhas abrem canais que ligam a pele ao meio externo. A abertura desses canais serve como porta de entrada de ativos de uso tópico nas camadas mais profunda da pele. Por isso, é recomendado aproveitar a técnica e associar a ativos com funções antioxidante, hidratante, clareador, antiglicante etc.

A eficácia do drug delivery induzida pela IPC tem sido apresentada em diversos estudos. Uma pesquisa intitulada "o uso da técnica de microagulhamento associada à vitamina C no tratamento de rejuvenescimento facial", objetivou elucidar os mecanismos relacionados ao microagulhamento e à sua associação com a vitamina C no processo de rejuvenescimento facial. E o resultado foi que a IPC foi eficaz na permeação da vitamina $C$ promovendo aumento na síntese de colágeno assim como ação antioxidante para rejuvenescer a face (GARCIA; LIMA e BOMFIM, 2017). 
Mais um importante recurso para tratar as peles envelhecidas é o peeling que significa descamação e se apresenta de dois tipos: os peelings químicos e físicos. Eles são procedimentos não invasivos que removem as camadas da pele e estimulam a renovação celular, promovendo assim a descamação cutânea. Necessariamente, peeling químico utiliza ácidos específicos para promover a renovação celular enquanto o peeling físico utiliza um processo de lixamento na pele.

O peeling químico também é denominado de quimioesfoliação e, basicamente, é um ácido que pode ser aplicado de forma tópica na pele a fim de remover, de forma controlada, as camadas da pele com consequente regeneração, o que resulta numa pele mais saudável. É sabido que há diferentes tipos de ácidos e com diferentes concentrações que podem ser aplicados para uma ação muito superficial, superficial, médio e profundo, ou seja, podem remover apenas a camada córnea ou até a derme reticular média (BESSA, 2020).

É sabido que os peeling químico têm inúmeros benefícios para a pele e é extremamente eficaz no combate ao seu envelhecimento, aliado ao fato de ser um tratamento rápido e que traz resultados desde a primeira aplicação (FERNANDES et al., 2018).

Um estudo de caso na qual se aplicou o peeling com ácido glicólico a 10\% na face em uma voluntária de 47 anos, fototipo II e com grau de envelhecimento moderado foi realizado na cidade de Cascavel, Estado do Paraná. No total foram 8 sessões de 40 minutos com intervalos semanais. A voluntária foi avaliada por questionário de satisfação e por análise fotográfica. O resultado foi a redução dos sinais da idade avançada, pois a pele ficou mais macia, uniforme, clara e revitalizada em um curto prazo. Confirmando que o ácido glicólico atua como esfoliantes que promove o aumento da renovação da epiderme e uniformização da pigmentação (ZDEBSKI et al., 2014). 
Outro estudo realizado na Índia sobre peelings químicos no tratamento na melanose facial (melasma, fotomelanose e pigmentação pós acne) demonstrou a eficácia deste tipo de terapia para revitalização da pele. A pesquisa foi um estudo cego, de controle paralelo e randomizado, de 36 casos, sendo 12 casos para cada disfunção dérmica (melasma, fotomelanose e pigmentação pós-acne). As voluntárias foram divididas em 3 grupos de 12 com suas respectivas lesões elementares da pele. E cada grupo foi dividido em 3 subgrupos: grupo 1 para ser tratado com peeling de ácido salić́lico (AS) 20\% aplicado uma vez em 2 semanas; grupo 2 para peeling de ácido glicólico (GA) 50\% aplicado uma vez em 3 semanas; e grupo 3 com ácido tricloroacético (TCA) 15\% aplicado uma vez em 3 semanas. O acompanhamento foi feito pela classificação da satisfação das voluntárias e por base em fotografias clínicas. O resultado foi que os peelings de GA, TCA e SA proporcionaram extraordinária resposta no melasma, fotomelanose e pigmentação pós-acne, respectivamente. Todos os 3 agentes de peeling foram bem tolerados sem nenhum efeito colateral significativo nas concentrações especificadas testada (CHOUDHARY; DHANDE e SINGH, 2017).

Dentre os peeling que obtiveram respostas satisfatórias na terapia do melasma que é uma hiperpigmentação na pele típica do fotoenvelhecimento se destacam o ácido tranexâmico, ácido ascórbico, ácido retinoico, solução de Jessner combinada com $15 \%$ de ácido tricloroacético, ácido glicólico e o ácido salićlicomandélico (BESSA, 2020). Além de clarear a pele, o peeling químico melhora aparência e textura da pele, reduz as rugas e marcas de expressão e diminuiu a oleosidade, logo é um poderoso rejuvenescedor.

Já os peelings físicos são de três tipos: de cristal que usa um pó de óxido de alumínio sobre a pele, o de diamante que promove a esfoliação através de uma ponta de lixa diamantada e o ultrassônico que emprega uma ponteira metálica que emite ondas ultrassônicas para retirar as células mortas da superfície da pele. Há também peelings físicos formulados com substâncias abrasivas veiculadas com cremes, emulsão, gel, gel-creme ou loções que retiram as primeiras camadas da pele.

RC: 97346

Disponível em: https://www.nucleodoconhecimento.com.br/saude/fisioterapiadermatofuncional 
O peeling de diamante é um recurso de microdermoabrasão que é constituído por um aparelho de pressão negativa junto com uma caneta de vidro ou acrílico e ponteiras diamantadas de diferentes granulometrias (50 a 200 micras). A sua utilização permite remover as células envelhecidas, estimular a produção de células novas e a neocolagênese. Em geral, ele é associado a aplicação de cosméticos, mas mesmo a sua ação isolada já produz benefícios para a pele.

Há estudos clínicos que comprovam que o peeling de diamante isolado ou associado a cosméticos é eficiente para tratar o envelhecimento facial. É o caso do ensaio clínico não controlado composto por 26 mulheres selecionadas por conveniência, com idade entre 25 e 55 anos. O estudo objetivou analisar os efeitos da microdermoabrasão através do peeling de diamante versus a sua associação com a vitamina $C$ tópica. Para participar do estudo as voluntárias precisariam ter sinais de envelhecimento facial, tais como: manchas, rugas e ressecamento. Elas foram avaliadas por ficha de exame fisioterapêutico, questionário de percepção da qualidade da pele e fotografia pré e pós o tratamento. Foram divididas em 2 grupos: grupo A: microdermoabrasão com peeling de diamante e grupo $B$ microdermoabrasão com peeling de diamante associado a vitamina $C$ tópica, Bio $C \circledast$ Home Care 10\% da marca Bel Col®. O tratamento durou 4 semanas, sendo aplicado uma vez por semana. Em ambos os grupos foi aplicado o peeling de diamante à 200 micras e com pressão do vácuo de -100 à $-200 \mathrm{mmHg}$, sendo que ao final, no grupo $\mathrm{B}$ foi acrescentado a vitamina $\mathrm{C}$. Em todas as voluntárias foi aplicado o protetor solar fator 30 , além de orientações quanto ao seu uso e evitar exposição ao sol. Como resultado, constatou-se a melhora visual nas rugas finas e sulcos faciais nos 2 grupos e sem diferença significativa. Porém, o tom da pele, textura e aparência geral foi mais bem percebida no grupo B. Logo, em ambos os grupos o resultado foi satisfatório (CAMPOS; CALEGARI e SILVA, 2017).

O peeling de cristal é outro recurso que pode ser utilizado no tratamento de rejuvenescimento facial. $O$ equipamento também trabalha com pressão negativa, porém a caneta possui duas cânulas, uma que ejeta os cristais de óxido de alumínio e outra que os aspira da pele. Os microcristais jateados sobre a superfície da pele

RC: 97346

Disponível em: https://www.nucleodoconhecimento.com.br/saude/fisioterapiadermatofuncional 
produzem a microabrasão para estimular os mecanismos de reparação e renovação da camada dermoepidérmica.

Um distúrbio típico de pele envelhecida é a hipercromia facial e para tratá-la existe o peeling de cristal. Ele representa um método não invasivo empregado para a revitalização e rejuvenescimento da pele. Esse tipo de peeling tem sido útil para o aumento da hidratação e controle da perda de água, porém seus resultados são momentâneos e obtidos logo após sua aplicação e com duração de apenas um dia após seu uso (DE ALMEIDA e FERRACINI, 2012).

Outro tipo de peeling que pode ser utilizado para tratar pele envelhecida é o peeling ultrassônico, pois emite ondas vibracionais que auxiliam a remover as células do extrato córneo e o excesso de secreção sebácea, promovendo a renovação celular, reduzindo a incidência de formações de comedões, fornecendo brilho e viço à pele. Este recurso permite uma esfoliação superficial da pele de forma indolor e sem produzir eritema. Pode ser utilizado de forma isolada ou por terapia combinada com ionização. Outros benefícios proporcionados por esse recurso são: higienização profunda, clareamento superficial, diminuição da oleosidade, melhora da oxigenação e revitalização da pele, hidratação da pele e introdução de cosméticos ionizáveis (SOUZA e NASCIMENTO, 2015).

Portanto, a microdermabrasão é um recurso que pode ser utilizado no tratamento do envelhecimento cutâneo, pois é eficaz para diminuir a espessura do estrato córneo, aumentar a circulação local, melhorar hidratação e síntese de colágeno e, com consequente, melhora do aspecto da pele (FERNANDES e DE OLIVEIRA ASSUNÇÃO, 2011).

Embora todos os recursos eletroestéticos possam proporcionar mais juventude e saúde à pele, os cosméticos são essenciais para potencializar e somar os benefícios alcançados. E quando se trata uma pele envelhecida é preciso atuar em vários pontos de disfunções que ela presenta, por isso, os ativos selecionados devem ter várias ações, tais como: hidratação, despigmentação, antioxidante, antiglicante, 
desglicante, controle de $\mathrm{pH}$, manutenção do manto hidrolipídico, nutrição, firmantes cutâneos e musculares, protetores contra UVA, UVB e luz visível etc. Um mesmo ativo pode ter mais de uma função, por isso é importante selecionar, sempre que possível, ativo multifuncional, pois irá atuar simultaneamente em várias alterações da pele.

Um exemplo é o ácido lactobiônico que é uma potente antioxidante, hidratante, além de melhorar o turn over celular e a firmeza da pele. Ele é uma excelente opção para peles fotoenvelhecidas e hiperqueratinizadas sem causar reações irritativas na pele (FERREIRA, 2019).

Outro exemplo é a vitamina $\mathrm{C}$ ou ácido ascórbico que é um ativo muito comum nas formulações cosméticas. Tem alta eficácia na ação antioxidante, mas também é um protetor na síntese de colágeno e elastina, além de ser um despigmentante, por isso colabora para desacelerar o envelhecimento celular da pele (DE OLIVEIRA, 2018).

Há vários ativos benéficos para pele envelhecida, resumidamente, como ativos antioxidantes, tem-se: coenzima Q10, extrato de green tea, Ginkgo biloba e idebenona; para hidratação, aquaderm, hidrovance, ureia de $1 \%$ a $10 \%$, aquaporine active, alantoína e aquaxyl; ativos firmantes como densiskin, rafermine, dimetilaminoetanol acetoamidobenzoato (DMAE), liftiline, vegetensor, easy lift e sesaflash; ativos dermorrelaxantes, argireline, leuphasyl e vialox poder (BORGES e SCORZA, 2016).

Os fatores de crescimento também são muito utilizados no tratamento da pele, pois a sua carência pode acelerar o processo de envelhecimento. Eles representam um grupo de numerosas moléculas de estrutura proteica biologicamente ativas que regulam o ciclo celular, dentre eles se destacam: PDGF, TGF $\alpha$, TGF $\beta$, EGF, FGF, KGF, IGF, VEGF e CTGF. Dessa forma, diversos fatores de crescimento são utilizados para promover a síntese de colágeno e combate aos sinais de envelhecimento, como rugas e flacidez facial (AMARAL et al, 2020). 


\section{CONSIDERAÇÕES FINAIS}

O envelhecimento é uma certeza que todos temos, porém, a busca pela preservação da aparência jovem tem sido um requisito para a idealização da beleza. Uma boa alimentação, prática regular de exercícios físicos e os tratamentos estéticos podem desacelerar o processo natural de envelhecimento do corpo, inclusive da pele.

Este estudo objetivou investigar os principais tratamentos estéticos e seus efeitos terapêuticos utilizados para manter a pele da face mais jovem e saudável. E foi possível constatar que a fisioterapia dermatofuncional utiliza um arsenal de condutas que podem hidratar, nutrir, melhorar o tônus cutâneo e muscular, despigmentar, estimular a síntese de colágeno e elastina, ter ações antioxidante, antiglicante e desglicante que resultam em uma pele mais jovial e saudável.

Vários recursos podem ser empregados pelo fisioterapeuta no processo de rejuvenescimento da face, tais como: radiofrequência, laser, luz intensa pulsada, led, microcorrentes, eletrolifting, microagulhamento, micropuntura, peelings e cosméticos. Todos esses recursos já possuem pesquisas que atribuem credibilidade aos seus efeitos, portanto, justifica a sua prescrição de forma isolada ou combinada.

\section{REFERÊNCIAS}

AMARAL, I.C.C et al. Revisão do uso de fatores de crescimento e suas evidências clínicas em procedimentos estéticos antienvelhecimento. Brazilian Journal of Surgery and Clinical Research, v. 31, n. 2, p. 96-105, jun/ago. 2020. Disponível em: https://www.mastereditora.com.br/download-3508. Acesso em: 10/07/2021.

BARBOSA, D.F. e CAMPOS, L.G. Os efeitos da corrente galvânica através da técnica de eletrolifting no tratamento do envelhecimento facial. Revista Inspirar: Movimento \& Saúde, São Paulo, v. 5, n. 1, p. 1-5, 2013. Disponível em: http://www.inspirar.com.br/wp-content/uploads/2013/03/corrente-galvanica-artigo292.pdf. Acesso em: 08/07/2021. 
BESSA, V.A.L. Tratamento do melasma com peelings químicos. Revista Científica Multidisciplinar Núcleo do Conhecimento, a. 5, ed.3, v. 7, p. 5-18, mar. 2020. doi: 10.32749/nucleodoconhecimento.com.br/saude/tratamento-do-melasma.

BESSA, V.A.L. e BESSA, M.F.S. O eletrolifting como uma alternativa no tratamento de estrias. Revista Científica Multidisciplinar Núcleo do Conhecimento, a.4, ed. 7, v. $11, \quad$ p. $67-78, \quad$ jul. $2019 . \quad$ doi: 10.32749/nucleodoconhecimento.com.br/saude/tratamento-de-estrias

BORGES, A.S.; SANTOS, K.C. e MOLZ, S. Fotobiomodulação: mecanismo de ação e eficácia no rejuvenescimento facial. Revista Eletrônica Biociências, Biotecnologia e Saúde, Curitiba, v. 12, n. 24, p. 60-69, maio/ago. 2019. Disponível em: https://revistas.utp.br/index.php/GR1/article/view/2446. Acesso em: 17/06/2021.

BORGES, F. S., e SCORZA, F. A. Terapêutica em estética: conceitos e técnicas. São Paulo, SP: Phorte, 2016.

CAMPOS V. B. et al. Estudo comparativo do laser fracionado não ablativo 1340nm para rejuvenescimento facial: alta energia com passagem única versus energia média e passagem tripla. Surg Cosmet Dermatol, v. 9, n. 3, p. 228-232, 2017 doi: http://dx.doi.org/10.5935/scd1984-8773.20179303. Acesso em: 05/06/2021.

CAMPOS, J.O.; CALEGARI, A. e SILVA, V. G. Os efeitos da microdermoabrasão com peeling de diamante associado à vitamina $c$ tópica no envelhecimento facial. Rev Inspirar Mov Saúde, v. 13, n. 2, p. 11-5, 2017. Disponível em: http://www.inspirar.com.br/wp-content/uploads/2017/05/revista-inspirar-ms-42-4762015.pdf. Acesso em: 10/07/2021.

CASTRO, E.S. e MENSCH, M. Envelhecimento facial: efeito da radiofrequência nas linhas e rugas de expressões. Revista Saber Científico, Porto Velho, v. 6, n. 2, p. 18, jan/dez, 2017. Disponível em: http://repositorio.saolucas.edu.br:8080/xmlui/bitstream/handle/123456789/2956/Eliz ete\%20de\%20Souza\%20Castro\%20-\%20Envelhecimento\%20facial\%20-

RC: 97346

Disponível em: https://www.nucleodoconhecimento.com.br/saude/fisioterapiadermatofuncional 
\%20efeito\%20da\%20radiofrequ\%C3\%AAncia\%20nas\%20linhas\%20e\%20rugas\%20 de\%20express\%C3\%B5es.pdf?sequence=1\&isAllowed=y. Acesso em: 12/07/2021.

CHOUDHARY, S; DHANDE, S e SINGH, A. Evaluation of various chemical peels in facial melanosis. IP Indian J Clin Exp Dermatol, v. 3, n. 2, p. 85-87, 2017. Disponível em: https://www.ijced.org/article-details/4484. Acesso em: 10/07/2021.

CRUZ, F.L.S. e PEREIRA, L.P. Estética facial: acupuntura no tratamento de rugas. Revista Saúde em Foco, n. 10, p. 181-185, 2018. Disponível em: revistaonline@unifia.edu.br. Acesso em: 22/06/2021.

DE ALMEIDA, C. da S. e FERRACINI, G. N. Eficácia do microdermoabrasão na hipercromia facial: revisão de literatura. Revista Inspirar Movimento \& Saude, v. 4, n. 4, p. 6-8, jul/ago. 2012. Disponível em: https://www.inspirar.com.br/wpcontent/uploads/2012/09/eficacia-microdermoabrasao-artigo-182.pdf. Acesso em: 10/06/2021.

DE OLIVEIRA, A. C. et. Efeitos do ácido ascórbico no combate ao envelhecimento cutâneo. BWS Journal, v. 1, p. 1-7, 2018. Disponível em: http://bwsjournal.emnuvens.com.br/bwsj/article/view/15. Acesso em: 08/07/2021.

DOS SANTOS, A. S.; OLIVEIRA, F. F. S. S. e CALDAS, É. C. Radiofrequência como coadjuvante no processo de rejuvenescimento facial. Revista Brasileira Interdisciplinar de Saúde, v. 4, n. 1, p. 55-59, 2019. Disponível em: https://revistarebis.rebis.com.br/index.php/rebis/article/download/109/101/232. Acesso em: 10/07/2021.

ESTRELA, J.V. et al. Efeito do led na flacidez tissular facial. Revista Científica da Escola de Saúde, CATUSSABA, v. 3, n. 2, p. 29-36, abr/set, 2014. Disponível em: https://repositorio.unp.br/index.php/catussaba/article/view/577. Acesso em: 10/07/2021. 
FERNANDES, A.C.F. et al. Peeling químico como tratamento estético. Revista Saúde em Foco. v. 10, p. 496-502, 2018. Disponível em: https://portal.unisepe.com.br/unifia/wpcontent/uploads/sites/10001/2018/07/061_PEELING_QUIMICO_COMO_TRATAME NTO_EST\%C3\%89TICO.pdf. Acesso em: 22/06/2021.

FERNANDES, M.J.S. e DE OLIVEIRA ASSUNÇÃO, F.F. Efeito do microdermabrasão no envelhecimento facial. Movimento, n. 3, p. 18-23, maio/jun. 2011. Disponível em: https://www.inspirar.com.br/wpcontent/uploads/2010/04/MICRODERMOABRASaO.pdf. Acesso em: 17/06/2021.

FERREIRA, L.A. O uso do ácido lactobiônico na pele fotoenvelhecida. Brazilian Journal of Natural Sciences, v. 2, n., p. 73-79, maio, 2019. doi: https://doi.org/10.31415/bjns.v2i2.51

GARCIA, F.S.; LIMA, L.T. e BOMFIM, F.R.C. O uso da técnica de microagulhamento associada à vitamina $\mathrm{c}$ no tratamento de rejuvenescimento facial. Revista Científica da FHO|UNIARARAS, v. 5, n. 1, p. 71-80, 2017. Disponível em: http://uniararas.br/revistacientifica/_documentos/art.019-2017.pdf. Acesso em: 17/06/2021.

HELFER, J.B. e MACHADO, G.R. Eletrolifting associado com nutricosmético no fotoenvelhecimento. In Anais Salão de Ensino e de Extensão. p. 155, 2017. Rio Grande do Sul: Universidade de Santa Cruz do Sul. Disponível em: https://online.unisc.br/acadnet/anais/index.php/salao_ensino_extensao/article/view/1 7110. Acesso em: 19/06/2021.

KIM, H.K. et al. Effects of lowlevel laser therapy, eletroacupuncture, and radiofrequency on the pigmentation and skin tone of adult women. Journal of Physical Therapy Science, v. 28, n., p. 1407-1411, 2016. doi: https://doi.org/10.1589/jpts.28.1407. Acesso em: 17/06/2021. 
LIMA, E. V. A.; LIMA, M. A. e TAKANO, D. Microagulhamento: estudo experimental e classificação da injúria provocada. Surgical \& Cosmetic Dermatology, Rio de Janeiro, v. 5, n. 2, p. 110-114, 2013. Disponível em: http://www.surgicalcosmetic.org.br/detalhe-artigo/261/Microagulhamento--estudoexperimental-e-classificacao-da-injuria-provocada. Acesso em: 15/06/2021.

MENDONÇA, A.C. et al. Efeitos da radiofrequência no envelhecimento cutâneo: uma revisão sistemática com metanálise. In Anais 4ำ Congresso Brasileiro de Fisioterapia Dermatofuncional. São Paulo: Associação Brasileira de Fisioterapia Dermatofuncional, p. 19, ago/set. 2018.

MORAES, E.N. Processo de envelhecimento e bases da avaliação multidimensional do idoso. In: Borges APA, Coimbra AMC, organizadores. Envelhecimento e Saúde da Pessoa Idosa, Rio de Janeiro: Fiocruz/ENSP/EAD, p. 151-175, 2008. Disponível em: http://www5.ensp.fiocruz.br/biblioteca/dados/txt_215591311.pdf. Acesso em: $17 / 06 / 2021$.

NOVAIS, M.D.J.A. e de SOUZA, É.P. Utilização de tratamentos estéticos no retardo do envelhecimento cutâneo: revisão integrativa. ID on line Revista de Psicologia, v. 14, n. 53, p. 950-961, 2020. Recuperado em https://idonline.emnuvens.com.br/id/article/view/2828. Acesso em: 12/07/2021.

PATRIOTA, R.C.R.; RODRIGUES, C.J. e CUCÉ, L.C. Luz intensa pulsada no fotoenvelhecimento: avaliação clínica, histopatológica e imuno-histoquímica. Anais Brasileiros de Dermatologia, Rio de Janeiro, v. 86, n. 6, nov./dez. 2011. Disponível em: https://www.scielo.br/j/abd/a/C55Vkc3pjvckBsssdqkMrLB/?format=pdf\&lang=pt. Acessado em: Acesso em: 11/07/2021.

PEREIRA, J. et al. Envelhecimento cutâneo e os cuidados estéticos na pele masculina. Revista Pesquisa e Ação, v. 5, n. 1, p. 26-34, jun. 2019. Disponível em: https://revistas.brazcubas.br/index.php/pesquisa/article/view/564. Acesso em: 12/07/2021. 
PORTELA, D.P e DUTRA, R. Inovações terapêuticas para rejuvenescimento facial: uma abordagem biomédica. Revista Eletrônica Biociências, Biotecnologia e Saúde, v. 12, n. 23, p. 27-38, maio/ago. 2019. Disponível em: https://seer.utp.br/index.php/GR1/article/view/2271/1892. Acesso em: 12/07/2021.

PROVENCIATO, J. M.; CASTRO, N. T. e CARVALHO, F. A eficácia da acupuntura no tratamento de rugas: revisão bibliográfica a partir de relatos clínicos. Humanidades \& Inovação, v. 6, n.13, p. 72-76, 2019 Disponível em: https://revista.unitins.br/index.php/humanidadeseinovacao/article/view/1520. Acesso em: 18/07/2021.

SANTOS, A.R.B. O uso do laser não ablativo no rejuvenescimento facial. Scire Salutis, v. 9, n. 1, p. 43-49, jan. 2019. doi: https://doi.org/10.6008/CBPC22369600.2019 .001 .0006

SANTOS, A.S. et al. Radiofrequência como coadjuvante no processo de rejuvenescimento facial. Revista Brasileira Interdisciplinar de Saúde, v. 2, n. 3, p. $55-9$ 2020.

Disponível

em: https://revistarebis.rebis.com.br/index.php/rebis/article/download/109/101/232. Acesso em: 12/07/2021.

SANTOS, E.S. A eficácia da estimulação elétrica por microcorrente em rugas periorbitais. Revista Multidisciplinar da Saúde, v. 7, n. 11, p. 29-36, 2015. Disponível em: https://revistas.anchieta.br/index.php/RevistaMultiSaude/article/view/997. Acesso em: 02/07/2021.

SANTOS, L.R.O.L.; NASCIMENTO, L.O.L.S. e BRITO, J.Q.A. Acupuntura como tratamento do rejuvenescimento facial: uma revisão literária. Id on Line Rev.Mult. Psic., v. 12, n. 40, p. 381-396, 2018. Disponível em: http://idonline.emnuvens.com.br/id. Acesso em: 12/07/2021. 
SOUZA, C.G.S. Acupuntura aplicada à estética facial para redução de rugas de expressão: ensaio clínico. (Tese de Doutorado). Universidade de São Paulo, São Paulo, 2020. doi: https://doi.org/10.11606/T.7.2020.tde-24022021-123549.

SOUZA, S. e NASCIMENTO, I.S. Estética facial e avaliação facial. Indaial: UNIASSELVI, 2015.

STROPARO, L. e DE SANTIS, S.A.C. Benefícios da luz intensa pulsada no envelhecimento cutâneo. Revista Eletrônica Biociências, Biotecnologia e Saúde, Curitiba, v. 13, n. 27, p. 56-67, 2020. Disponível em: https://interin.utp.br/index.php/GR1/article/view/2633. Acesso em: 12/07/2021.

Teixeira, I.N.D.O. e Guariento, M.E. Biologia do envelhecimento: teorias, mecanismos e perspectivas. Ciênc. Saúde Coletiva, v. 15, n. 6, p. 2845-2857, set. 2010. doi: https://doi.org/10.1590/S1413-81232010000600022.

YUN, Y. et al. Efeito da acupuntura cosmética facial na elasticidade facial: um estudo piloto de rótulo aberto e de braço único. Medicina Alternativa e Complementar Baseada em Evidências: eCAM, v. 2013, p. 1-5, jul. 2013. doi: https://doi.org/10.1155/2013/424313

ZACHARY, C. B. Facial Rejuvenation: 40th Anniversary Review. Seminars in Cutaneous Medicine and Surgery, v. 35, n. 6 Suppl, p. S122-S124, 2016. doi: https://doi.org/10.12788/j.sder.2016.039

ZDEBSKI, A.C. et al. Utilização do ácido glicólico a 10\% para revitalização de peles maduras. Revista Thêma et Scientia, v. 4, n.1, p. 127-130 jan/jun. 2014. Disponível em: https://www.fag.edu.br/upload/arquivo/1431177663.pdf. Acesso em: 12/07/2021.

Enviado: Julho, 2021.

Aprovado: Setembro 2021. 